\title{
The interaction of EDTA with barium sulfate
}

Franca Jones*, Phillip Jones\#, Mark I. Ogden\#, William R. Richmond\#, Andrew L. Rohl†\#, Martin Saunders $\wedge$.

*corresponding author: AJ Parker CRC for Integrated Hydrometallurgical Solutions, Nanochemistry Research Institute, Department of Applied Chemistry, Curtin University of Technology, GPO Box U1987, Perth WA 6845 Australia.

Phone: $61892667677 \quad$ Fax: $61892664699 \quad$ Email: F.Jones@curtin.edu.au

\#Nanochemistry Research Institute, Department of Applied Chemistry, Curtin University of Technology, GPO Box U1987, Perth WA 6845 Australia.

$†$ iVEC 'The hub of advanced computing in Western Australia', 26 Dick Perry Avenue, Technology Park, Kensington WA 6151 Australia

^ Centre for Microscopy, Characterisation and Analysis, University of Western Australia, Crawley, W.A., 6009, Australia 


\section{Abstract}

The carboxylate molecule EDTA (ethylenediaminetetraacetic acid) is a known complexing agent that interacts with a host of cations. In this paper, various techniques are used to elucidate the mechanism of interaction between EDTA and barium sulfate. It is shown that complexation is not sufficient to explain the inhibition of barite crystallization but that other processes such as chemisorption must also occur. Interestingly, regardless of the solution speciation, EDTA is shown to adsorb in the deprotonated form - suggesting that the molecule is able to lose a proton when it adsorbs at lower pHs. Molecular modelling shows that the interaction of the surface barium ions with the carboxylate group is an important one: underlying the reason why these molecules are good at complexing cations. Finally, in-situ turbidity measurements are obtained in order to determine the mechanism of nucleation/growth modification. It is found that this organic molecule inhibits nucleation and that this could be its primary means of inhibiting precipitation of barium sulfate.

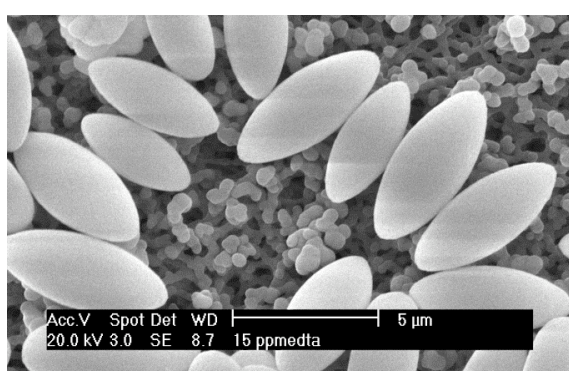

Although the aminocarboxylate, ethylenediaminetetraacetic acid, is a known complexing agent, the mechanism by which it inhibits barium sulfate precipitation is better explained by adsorption onto critical nuclei. 


\section{The interaction of EDTA with barium sulfate}

Franca Jones*, Phillip Jones\#, Mark I. Ogden\#, William R. Richmond\#, Andrew L. Rohl†\#, Martin Saunders^.

*corresponding author, AJ Parker CRC for Integrated Hydrometallurgical Solutions, Nanochemistry Research Institute, Department of Applied Chemistry, Curtin University of Technology, GPO Box U1987, Perth WA 6845 Australia.

Phone: $61892667677 \quad$ Fax: 61892664699 Email: F.Jones@curtin.edu.au

\#Nanochemistry Research Institute, Department of Applied Chemistry, Curtin University of Technology, GPO Box U1987, Perth WA 6845 Australia.

$†$ iVEC 'The hub of advanced computing in Western Australia', 26 Dick Perry Avenue, Technology Park, Kensington WA 6151 Australia

$\wedge$ Centre for Microscopy, Characterisation and Analysis, University of Western Australia, Crawley, W.A., 6009, Australia

\section{Abstract}

The carboxylate molecule EDTA (ethylenediaminetetraacetic acid) is a known complexing agent that interacts with a host of cations. In this paper, various techniques are used to elucidate the mechanism of interaction between EDTA and barium sulfate. It is shown that complexation is not sufficient to explain the inhibition of barite crystallization but that other processes such as chemisorption must also occur. Interestingly, regardless of the solution speciation, EDTA is shown to adsorb in the deprotonated form - suggesting that the molecule is able to lose a proton when it adsorbs at lower pHs. Molecular modelling shows that the interaction of the surface barium ions with the carboxylate group is an important one: underlying the reason why these molecules are good at complexing cations. Finally, in-situ turbidity measurements are obtained in order to determine the mechanism of nucleation/growth modification. It is 
found that this organic molecule inhibits nucleation and that this could be its primary means of inhibiting precipitation of barium sulfate.

Keywords: barium sulfate, molecular modelling, precipitation, infrared spectroscopy, speciation, adsorption isotherms, inhibitors, amino-carboxylates, scale

\section{Introduction}

Barium sulfate is a known scale producing precipitate in many industrial and oil drilling processes [1-3]. Work within our group has focussed on trying to understand, at a fundamental level, the interactions of inhibitor molecules with the surfaces of barium sulfate [4-7]. Additionally, it would be valuable if information from modelling could be correlated to inhibition and vice versa. To this end we have conducted several studies employing both computational and experimental techniques in order to obtain this information $[8,9]$. Ethylenediaminetretraacetic acid (EDTA) is a particularly interesting molecule to investigate since many consider its only action in growth inhibition experiments is that of a complexation agent. If this is true then the effect of EDTA is on solution species only, i.e. EDTA complexes cations in solution thus reducing the free ions available to participate in the crystallization process and results in a lower supersaturation. It will be shown in this paper that EDTA does not only operate in this manner and that direct EDTA-surface interactions must also play a part.

AFM studies have tended to concentrate on the dissolution of barite and have shown that the etch pits in the presence of EDTA have a different morphology than those formed in pure water $[10,11]$. However, this work was conducted at high $\mathrm{pH}(\mathrm{pH}=12)$ and subsequent work has shown the same etch pit morphology occurs at high ionic 
strength [12] in the absence of EDTA. Thus, it is not clear if the changes observed are caused solely by the high ionic strength, or if the EDTA plays a significant role. In this work, we have purposely avoided such high $\mathrm{pHs}$ in order to avoid such ambiguities. The only other literature (not from our group) to mention barite and EDTA is that of Uchida $[13,14]$ where once again EDTA is used for its complexing ability (at high $\mathrm{pH}$ ) and is shown to affect the morphology of barite. The role of EDTA as a complexing agent necessitates that sufficient EDTA be present to complex enough cations in solution to appreciably affect the supersaturation. Thus, if EDTA is complexing barium ions in solution it cannot act as a threshold inhibitor (i.e. an inhibitor that is efficacious at very low concentrations, meaning that too little inhibitor is present to affect the supersaturation) .

In an effort to obtain both ex situ and in situ information, several techniques have been used here to investigate barium sulfate crystallization in the presence of EDTA. Results from FTIR spectra, speciation curves and molecular modelling have all been gathered together and used to interpret in-situ conductivity and turbidity measurements that give information on the precipitation rate. Acquisition of FTIR spectra of EDTA on barium sulfate surfaces was possible since the infrared absorbances of EDTA are not in the same wavenumber region as the sulfate bands of the barite. Interpretation of these spectra has been achieved with the aid of speciation curves, relevant literature and molecular modelling. 


\section{Experimental}

\section{Conductivity and turbidity}

Conductivity results have been previously reported [4-7] and these were used to obtain de-supersaturation information in situ. Put simply, the comparison of the desupersaturation rates with and without inhibitor present determine the degree to which precipitation is inhibited. Turbidity is used to measure the induction time [15], which is in turn related to the nucleation rate. Inhibitors can be nucleation inhibitors, growth inhibitors or both. Both methods consisted of equilibrating $0.25 \mathrm{mM} \mathrm{BaCl}_{2}$ (toxic salt) to $25^{\circ} \mathrm{C}$, inserting the relevant probe and adding a stoichiometric amount of $\mathrm{Na}_{2} \mathrm{SO}_{4}$ to commence precipitation. Data was continuously logged to a computer for later analysis. The samples were filtered after each experiment and then prepared for scanning or transmission electron microscopy (SEM or TEM). Scanning Electron Micrographs were recorded on a Philips XL30 microscope. Transmission Electron Microscopy was carried out on a JEOL 2100 TEM operating at 120kV. Samples for TEM were resin-embedded cross-sections supported on holey carbon grids.

\section{Molecular modelling}

Molecular modelling of inhibitor molecules on flat barium sulfate surfaces has previously been published $[8,16]$. The parameters derived specifically for EDTA can be found in [8]. The molecular modelling was conducted using empirical potentials, the parameters of which were fitted to known constants or suitably derived. A schematic of EDTA is given in Figure 1 below. 


\section{Infrared}

Infrared spectra were obtained on a Bruker IFS 66 instrument using the Horizontal Attenuated Total Reflection (HATR) accessory. The resolution was $4 \mathrm{~cm}^{-1}$ and an MCT (Mercury Cadmium Telluride) detector was used. The aperture was $12 \mathrm{~mm}$ and 256 scans were obtained for all spectra. A small particle size (high surface area) barium sulfate was prepared at extremely high supersaturations by mixing $\mathrm{BaCl}_{2}(0.5 \mathrm{M}, \mathrm{pH} 3)$ and $\mathrm{Na}_{2} \mathrm{SO}_{4}(0.5 \mathrm{M}, \mathrm{pH} 3)$ with magnetic stirring. At this $\mathrm{pH}$, agglomeration of the particles formed could be avoided by surface charge repulsion. The solids were analysed for particle size distribution (using a Malvern Mastersizer) and surface area (using BET, nitrogen as the carrier gas). The mean radius of the particles was found to be $\sim 270 \mathrm{~nm}$ with $90 \%$ of particles below $560 \mathrm{~nm}$ and the surface area was found to be $7.4 \mathrm{~m}^{2} / \mathrm{g}$.

The adsorption experiment consisted of equilibrating $30 \mathrm{~mL}$ of EDTA solution (at a given concentration) with $0.10 \mathrm{~g}$ barite solids and adjusting to the desired $\mathrm{pH}$ with small amounts of $\mathrm{HCl}$ or $\mathrm{NaOH}$. The $\mathrm{pH}$ was further adjusted after 24 hours if necessary and re-equilibrated for a final 24 hours. The adsorbed organic spectra were obtained by subtracting the spectra of barium sulfate in solution at a given $\mathrm{pH}$ from the spectra of the organic+barium sulfate in solution at the same $\mathrm{pH}$. This does, however, imply that some contribution is made by the dissolved organic (in solution) to the spectra. This is expected to be small given the small penetration depth (of the evanescent wave) and the high surface area of the barium sulfate used. The differences observed between the solution spectra and the adsorbed spectra confirm that the solution species did not significantly impact the infrared results. 


\section{Speciation curves}

Speciation curves were calculated using the Hyss program [17]. Equilibrium constant data, both for protonation and complexation reactions, were obtained from the on-line JESS thermodynamic database [18].

\section{Results and Discussion}

\section{Conductivity, morphology and turbidity}

To fully understand how EDTA interacts with barite, it is essential that both the solution chemistry of EDTA and its surface activity onto barite is taken into consideration.

First, let us turn to the solution behaviour of EDTA. In solution, the protonation state of EDTA naturally depends on the $\mathrm{pH}$ (shown in Figure 2). This changes when other cations are present due to formation of complexes with EDTA. Figure $2 \mathrm{~B}$ shows that the barium ion is at most $40 \%$ complexed with EDTA at $\mathrm{pH} 6$ (when the ligand and ion are present at 1:1). This complex is in the form $\mathrm{LBa}^{2-}$ where $\mathrm{L}$ refers to the fully deprotonated ligand. Note, this uses a high complexation constant (ln K) for the formation of $\mathrm{LBa}^{2-}$ of 9.336 and will be even less $(<10 \%)$ if other, smaller values are used (values for $\ln \mathrm{K}$ of the complexation reaction range from $7-9.336$ with most being $~ 7.5[18])$, thus this is an upper estimate.

Conductivity results show that EDTA is able to inhibit precipitation of barium sulfate provided suitable concentrations are present (Figure 3A). Similarly, turbidity measurements showed that the nucleation rate is slowed with increasing EDTA up to $\sim 5$ ppm (Figure 3B, this is roughly 1:16 $\mathrm{EDTA} \mathrm{Ba}^{2+}$ ). Thus, EDTA impacts on the nucleation rate of barium sulfate at very low levels. This impact can be seen in the 
morphology of the particles obtained in the presence of EDTA as shown in Figure 4. The morphology change observed in the presence of EDTA cannot be explained on the basis of a lowered supersaturation. As supersaturation decreases, the barite particle morphology transforms from the 'pillow-shaped' particles to rhombohedral particles [19].

From the conductivity data, it can be seen that EDTA decreases the de-supersaturation rate as concentration increases (Table 1). The initial $\mathrm{Ba}^{2+}$ concentration in solution is $0.249 \mathrm{mM}$.

The notion that a simple lowering of supersaturation is the only mechanism behind all of these phenomena is not tenable. Most obviously, the morphology change in the barium sulfate particles implies that some adsorption process is occurring. In terms of morphology, the dramatically different form of barite observed, compared to when supersaturation is decreased, suggests that the effect is due to direct EDTA-barite surface interactions. The rice shaped particles in Figure 4 indicate that EDTA interacts with the (011) face in a manner similar to that observed for phosphonates by the group of Davey [20].

In addition, even at very low EDTA levels, inhibition is occurring to some extent. For example, at $0.016 \mathrm{mM}$ (5 ppm) EDTA, at most $42-45 \%$ of the EDTA is expected to be complexed with $\mathrm{Ba}$ in the $\mathrm{LBa}^{2-}$ form. This would still leave a $\mathrm{Ba}^{2+}$ ion concentration of $0.243 \mathrm{mM}$ and therefore lead to a lowering of the supersaturation ratio by only $1.5 \%$ ( $S=25$ initially, $S=24.6$ after complexation) yet we see an inhibition of $16 \%$ at this level. It is true that de-supersaturation rate is not linear with supersaturation but the reduction is nevertheless more significant than expected. Another reason why it is clear that the 
mode of action of EDTA is more than just a complexation effect is the effect on nucleation. As shown in Figure 3B, the turbidity curves obtained for precipitation of barium sulfate in the presence of different EDTA concentrations at $\mathrm{pH} \sim 6$ (unseeded) show that the induction time increases (nucleation rate decreases) as the concentration increases. Since complexation at $1 \mathrm{ppm}(0.003 \mathrm{mM})$ EDTA only lowers the supersaturation by $0.002 \%$, the effect on nucleation must be due to some other mechanism. Also, note that the effect on nucleation is not significantly altered on going from $5 \mathrm{ppm}(0.016 \mathrm{mM})$ to $15 \mathrm{ppm}(0.049 \mathrm{mM})$ EDTA.

The barite basal face observed at $50 \mathrm{ppm}(0.16 \mathrm{mM})$ EDTA cannot be unambiguously assigned using SEM alone. Ultramicrotomed samples of barite particles formed in the presence of EDTA were viewed using a Transmision Electron Microscopy (TEM) and Selected Area Electron Diffraction (SAED) patterns were obtained. Due to the random orientation in which the particles can be set within the resin, only those particles that appeared whole, lying completely on the basal plane and, where possible, in an area of the grid without other particles around them were chosen. These particles showed a consistent diffraction pattern; an example is shown in Figure 5. Analysis of the d spacings obtained for the SAED gave the (010) face as the basal face.

The precipitation experiments were also conducted at higher temperatures since barite scale in the petroleum industry is commonly formed under such conditions. The control particles at $\sim 80{ }^{\circ} \mathrm{C}$ are thicker and the aspect ratio is closer to 1 than at $25^{\circ} \mathrm{C}$. At higher temperatures and with EDTA present, the barite particles are similar to those formed at the lower temperatures but are somewhat blockier. As per the control, the aspect ratio is closer to one and as the EDTA concentration increases, the particles become flatter; this 
too was observed at the lower temperature. Thus, essentially, the EDTA affects morphology in much the same way at higher temperatures as it does at lower temperatures. At the higher temperature and at lower concentrations however, rice shaped particles are not observed, although at $0.049 \mathrm{mM}$ EDTA there is a hint of the (011) face as observed by the rounding of the corners.

\section{FTIR}

The speciation curve for EDTA (Figure 2) in solution shows that at $\mathrm{pH} 5$ it is almost entirely present as the $\left(\mathrm{NCH}_{2}\right)_{2}\left(\mathrm{CH}_{2} \mathrm{COO}\right)_{4} \mathrm{H}_{2}{ }^{2-}$ molecule $\left(\right.$ or $\left.\mathrm{H}_{2} \mathrm{~L}^{2-}\right)$. As $\mathrm{pH}$ increases to 8, $\left(\mathrm{NCH}_{2}\right)_{2}\left(\mathrm{CH}_{2} \mathrm{COO}\right)_{4} \mathrm{H}^{-}$dominates $\left(\mathrm{HL}^{3-}\right)$. Thus, a proton is lost on going from $\mathrm{pH}$ 5-8.

Literature gives the asymmetric $\mathrm{COO}^{-}$stretch values ranging from $1550-1650 \mathrm{~cm}^{-1}$ depending on the coordination of EDTA [21]. The symmetric $\mathrm{COO}^{-}$stretches lie in the $1350-1450 \mathrm{~cm}^{-1}$ region. Figure 8 shows the solution spectra of EDTA (in the absence of barium sulfate) at different pHs. At pH 5 the asymmetric stretch is found at $1619 \mathrm{~cm}^{-1}$ consistent with the literature. As $\mathrm{pH}$ increases, the asymmetric stretch does not change significantly. The free $\mathrm{C}=\mathrm{O}$ stretch for EDTA is found at $1726 \mathrm{~cm}^{-1}$ [22] and was not observed for any of the spectra. The HATR spectra of EDTA in solution shows that as pH increases, the band at $\sim 1360 \mathrm{~cm}^{-1}$ disappears (Figure 7). This supports the speciation data (Figure 2), showing that a proton is lost from the EDTA molecule as the $\mathrm{pH}$ increases from 5 to 8 . Thus, it is clear that this peak must be associated with the protonation state of EDTA and is not a symmetric $\mathrm{COO}^{-}$stretch. This is also supported by literature [21] where $\mathrm{H}_{2} \mathrm{~L}$ is observed to have the same FTIR spectra as shown for our $\mathrm{pH} 5$ sample (where the $\mathrm{H}_{2} \mathrm{~L}$ species is expected to exist). The symmetric $\mathrm{COO}^{-}$ stretch can now be assigned as that occurring at $\sim 1400 \mathrm{~cm}^{-1}$ in all of the spectra. 
The adsorbed EDTA (on barium sulfate) spectra show (Figure 8) that independent of $\mathrm{pH}$, the EDTA spectrum of the adsorbed species appears to have the same structure as the solution EDTA species observed at $\mathrm{pH} 8$ (due to the absence of the $1360 \mathrm{~cm}^{-1}$ peak). This was also true for all concentrations investigated above the detection limit. Comparison with the speciation curve suggests a mono-protonated EDTA (where the proton is bonded to the nitrogen due to zwitterion formation [23]). There appears to be a shoulder between $1675-1660 \mathrm{~cm}^{-1}$ however, the dominant $\mathrm{COO}^{-}$asymmetric stretch is now found at $\sim 1575 \mathrm{~cm}^{-1}$ for all $\mathrm{pHs}$. This movement of the asymmetric stretch to lower wavenumbers suggests a chemisorption process. The shoulder could be due to some coordinated $\mathrm{COOH}$, however, according to Faulques et al. [22], the lack of protonated carboxyl groups at $\mathrm{pH} 8$ (since the proton will be on the nitrogen) implies that the 1675 $1650 \mathrm{~cm}^{-1}$ shoulder is perhaps due to hydrogen bonding from the zwitterion with the carboxylate rather than the presence of any carboxylic acid moiety.

To the best of our knowledge, this is the first time it has been shown that an adsorbed species is different to, and independent of, the solution species. Thus, while the EDTA molecule might be in the di-protic state in solution (for those $\mathrm{pHs}<7$ ) the surface is able to deprotonate the molecule on adsorption. There is a hint of protonated species for the pH 5 spectrum, however, this could be due to a small contribution from the solution and may not actually be due to the adsorbed species.

\section{The effect of calcium}

The presence of calcium cations changes the behaviour of EDTA during the precipitation of barite. The role of calcium has been a point of discussion for many years. Certainly, when comparing solutions with and without calcium ions present, 
inhibitors can appear to inhibit better in the presence of calcium ions. However, calcium ions impart their own substantial impact on barium sulfate precipitation [19]. Thus, in order to know whether the presence of calcium ions increases or decreases the precipitation rate, the comparison must be made with the same ionic strength and supersaturation as the control. In addition, any interpretation of what occurs in the presence of calcium must also include what happens to the EDTA solution chemistry in the presence of calcium cations. Figure 9 shows the solution speciation curves for EDTA in the presence of calcium ions.

When calcium ions are present, the EDTA is almost fully complexed by $\mathrm{pH} 6$ at 1:1 concentrations. Thus, EDTA will preferentially complex to calcium over barium ions. In mixed systems then, very little barium ion complexation occurs, while the EDTA is almost completely complexed with calcium.

As shown in ref [24] the presence of calcium ions and EDTA during barite precipitation leads to a lower inhibitory response. Thus, the presence of calcium ions increases the de-supersaturation rate when compared to an appropriate control [24]. Recall, when barium sulfate is precipitated in the presence of EDTA only, increasing concentrations show an increasing induction time. We know then, that on its own EDTA can be a nucleation inhibitor but with calcium present this does not occur. We also know that calcium is complexed by EDTA at these concentrations and that this complexed species does not affect morphology (see Figure 10).

If complexed EDTA does not induce morphological changes in barium sulfate then this must suggest that either it does not participate in precipitation or that these species are 
incorporated early on in precipitation (possibly as part of the critical nuclei) and are not available to influence morphology by adsorption. From our work with zinc cations [25], it appears that the lack of morphological effect on barium sulfate by EDTA in the presence of calcium is most probably due to the complexed EDTA not being surface 'active'. That is, it is only the uncomplexed EDTA that is able to affect the morphology by directly adsorbing onto the barium sulfate surface.

\section{Molecular Modelling}

At $\mathrm{pH}$ 7-8 EDTA exists mainly as the $\mathrm{HL}^{3-}$ species, where the proton would be expected to bond to the nitrogen atom. At lower pHs the dominant species is $\mathrm{H}_{2} \mathrm{~L}^{2-}$ in solution, however, the infrared results suggested that the adsorbed EDTA is in the form of $\mathrm{HL}^{3-}$. Thus, in our computer simulations we chose to model the EDTA molecule as shown in Figure 1 but fully de-protonated, i.e. as the $\mathrm{L}^{4-}$ species (without the zwitterion). The measure of the likelihood of an additive adsorbing on a surface is given by its replacement energy [26] as described in Equation 1. In the system investigated here, the replacement energy refers to the energy required to replace a surface sulfate ion with an EDTA ion. Thus, the more negative the replacement energy, the more likely the replacement reaction (adsorption) is likely to occur.

$\mathrm{E}_{\text {rep }}=\left(\mathrm{E}_{\text {surf }+ \text { additive }}+\mathrm{n}\left\{\mathrm{E}_{\text {sulf }}+\mathrm{E}_{\text {solvSO4 }}\right\}\right)-\left(\mathrm{E}_{\text {surf }}+\left\{\mathrm{E}_{\text {additive }}+\mathrm{E}_{\text {solvAdd }}\right\}\right) \quad$ Eqn 1.

$\mathrm{E}_{\text {surf+additive }}$ is the energy of the system with the additive adsorbed, $\mathrm{n}$ is the number of sulfates removed from the surface in order to adsorb the additive (for the L $^{4-}$ EDTA species, this requires $n=2$ ), $E_{\text {sulf }}$ is the energy of the isolated sulfate ion and $E_{\text {solvsO4 }}$ is the corresponding solvation energy of the sulfate, $\mathrm{E}_{\text {surf }}$ is the energy of the surface with the sulfates still in the lattice, $\mathrm{E}_{\text {additive }}$ is the energy of the free additive (in this case EDTA) and $\mathrm{E}_{\text {solvadd }}$ is the corresponding solvation energy of the additive. 
The replacement energy for EDTA on seven barite faces follows the order below:

$(011)>(100 \mathrm{a})>(010)>(210)>(101)>(001)>(100 \mathrm{~b})>(211)$

(the surface of the 100 face can be cleaved in two distinct way and so both terminations have been studied and are termed 100a and 100b, see refs [8, 9] for further details). Figure 11 shows the adsorbed configurations of the two most energetically favoured faces for EDTA. For many of the EDTA configurations, the carboxylate groups do not lie within the surface. This is true for the (011) face, which is the most energetically favoured configuration. However, the carboxylate oxygen atoms are all within a distance to interact significantly with at least one and, in most cases, two surface barium atoms. The only EDTA configuration to show all four carboxylate groups within the surface is that on the (100a).

From the modelling results we can see that the surface bound EDTA anions do not assume a convergent conformation as typically observed when the ligand is bound to a single metal cation. For example, the central dihedral N-C-C-N angles are $155^{\circ}(011$ face) and $178^{\circ}$ (100 face), compared to those reported in structurally characterized barium edta complexes, at $41^{\circ}$ and $63^{\circ}$ [27]. The EDTA N...Ba distances in the calculated structures also do not suggest any significant interactions. It is interesting to note that the metal-carboxylate binding modes differ in the two surface calculations. On the $(011)$ face, a common feature is the bidentate chelation of the carboxylate moiety to a barium cation, with a bridging interaction of one or both of the $\mathrm{O}$ atoms to an additional barium cation. The resulting barium... barium distances range from 4.1 to 4.5 $\AA$, which compares to a Ba...Ba distance in the original surface of $4.64 \AA$. On the (100) face, the common metal-carboxylate interaction is syn-syn or anti-syn bridging, with 
each $\mathrm{O}$ atom of the carboxylate group interacting in a unidentate manner with a single barium cation. The Ba...Ba interactions range from 5.1 to $6.1 \AA$. The initial surface Ba...Ba distance is $5.45 \AA$. Thus it appears that the surface structure has an impact on the coordination mode of the surface bound EDTA molecule. The experimentally observed FTIR spectra will, of course, be an average of all these interactions, as well as any differences induced by the presence of water. Due to the necessity of simplifying this simulation, zwitterion formation was not investigated and so the results presented here pertain only to the carboxylate interactions with the barium sulfate surface. However, previous modelling comparing the presence or absence of the zwitterion suggests that its impact is small and only increases the strength of the adsorption process by the ability of the zwitterion to hydrogen bond to the surface [28].

In comparison to the experimentally observed results on the morphology (see Figures 4 and 6), the rounded edges forming 'rice' shaped particles of barium sulfate appears to be the signature of particles formed in the presence of a growth modifier with a strong interaction on the (011) face as demonstrated by phosphonate additives also found to have a strong interaction on the (011) [20] and shown schematically in [9]. At higher concentrations, the particles are flatter. This is also observed when barite is precipitated in the presence of a triphosphonate; in this case the flat section of the particle was shown, via selected area diffraction, to be the (100) [9]. In the presence of EDTA this flat face was found to be the (010) (from TEM SAED shown in Figure 5). What is interesting is that experimentally as temperature is increased, the (011) interaction is not observed. There are two possible explanations for these observations; one is that as temperature increases, kinetic effects become important and this impacts on the morphology observed, the other is that as temperature increases the sequence of 
favoured faces could alter. In addition to these possibilities is that the modelling conducted here is on flat surfaces and crystallization is known to occur via step, kink or spiral growth mechanisms, thus differences in the replacement energy ordering might be expected if modelled on these growth features. This could also be important in explaining why we observe the (010) interaction in preference to the (100) interaction. Overall, however, this relatively simple model has been able to determine those faces most likely to be affected and the experimental results confirm these results overall (at room temperature the (011) and (010) interaction are observed, while at high temperature the (210), (100), (010) interactions are observed).

\section{Summary and Conclusions}

It is often assumed that the action of carboxylates such as EDTA is purely by complexation of ions in solution, reducing the activity of such ions. However, it has been demonstrated in this work that such an assumption is erroneous.

Firstly, the degree of barium complexation in solution is not sufficient to explain the effects on turbidity and to a lesser extent on conductivity behaviour. Secondly, the impact on morphology is not the same as that observed when supersaturation is reduced. Furthermore, it has been shown by infrared spectroscopy that chemisorption of the EDTA molecule occurs onto barium sulfate. Interestingly, regardless of the solution speciation, EDTA is shown to adsorb in the de-protonated form - suggesting that the molecule is able to lose a proton when it adsorbs from solutions at lower pHs.

The turbidity results show that nucleation is slowed when even low levels of EDTA are present. Thus, EDTA must affect the critical nuclei. Molecular modelling was able to 
show that the interaction of the surface barium atoms with the carboxylate group is an important one and that the corresponding faces that were found to have the lowest replacement energies were those that were also observed experimentally.

Finally, the presence of calcium appears to reduce the ability of EDTA to inhibit barium sulfate crysallization. The morphology of the barium sulfate when both calcium and EDTA are present is unaffected by the EDTA and this could be due to there not being free EDTA to interact with the barium sulfate nuclei.

\section{Acknowledgements}

F. Jones gratefully acknowledges that this research has been supported under the Australian Government's Cooperative Research Centre (CRC) Program, through the Parker CRC for Integrated Hydrometallurgy Solutions. Transmission electron microscopy was carried out using facilities at the Centre for Microscopy, Characterisation and Analysis, The University of Western Australia, which are supported by University, State and Federal Government funding.

\section{References}

[1] K. S. Sorbie and E. J. Mackay, J. Petroleum Sci. Eng., 27 (2000) 85-106.

[2] W. J. Benton, I. R. Collins, I. M. Grimsey, G. M. Parkinson, and S. A. Rodger, J. Chem. Soc. Faraday Disc., 95 (1993) 281-297.

[3] P. J. Breen, H. H. Downs and B. N. Diel, Spec. Publ. - R. Soc. Chem., 97 (1991) 186-98.

[4] F. Jones, J. Clegg, A. Oliveira, A. L. Rohl, M. I. Ogden, G. M. Parkinson, A. M. Fogg, M. M. Reyhani, CrystEngComm, 40 (2001) 1-3. 
[5] F. Jones, A. Oliveira, A. L. Rohl, M. I. Ogden, G. M. Parkinson, and M. M. Reyhani, Journal of Crystal Growth, 237-239 (2002) 424-429.

[6] M. M. Reyhani, , A. Oliveira, G. M. Parkinson, F. Jones, A. L. Rohl, M. I. Ogden, Int. J. Modern Physics B., 16(1\&2) (2002) 25-33.

[7] F. Jones, A. Stanley, A. Oliveira, A. L. Rohl, M. M. Reyhani, G. M. Parkinson, M. I. Ogden, J. Crystal Growth, 249 (2003) $584-593$.

[8] F. Jones, A. L. Rohl, Molecular Simulations, 31(6-7) (2005) 393-398.

[9] F. Jones, W. R. Richmond, A. L. Rohl (2006) J. Phys. Chem. B, 110 7414-7424.

[10] K-S.Wang, R. Resch, K. Dunn, P. Shuler, Y. Tang, B. E. Koel, T. F. Yen, Langmuir, 16 (2000) 649-655.

[11] K. Dunn, T. F. Yen, Environmental Sci. \& Technol., 33(16) (1999) 2821-2824.

[12] P. Risthaus, D. Bosbach, U. Becker, A. Putnis, Colloids and Surfaces A, 191 (2001) 201-214.

[13] M. Uchida, A. Sue, T. Yoshioka, A. Okuwaki, J. Mater. Sci. Lett., 19 (2000) 13731374.

[14] M. Uchida, A. Sue, T. Yoshioka, A. Okuwaki, Cryst. Eng. Comm., 5 (2001) 1-6.

[15] O Söhnel \& J. Garside (1992) in, "Precipitation. Basic Principles and Industrial Applications”, Butterworth-Heinemann Ltd, Oxford.

[16] a) A. M. Fogg, A. J. Freij, A. L. Rohl, M. I. Ogden and G. M. Parkinson, J. Phys. Chem. B 106 (2002) 5820-5826. b) A. M. Fogg, A. J. Freij, A. Oliveira, A. L. Rohl, M. I. Ogden, and G. M. Parkinson, J. Cryst. Growth, 234 (2002) 255-262.

[17] L. Alderighi, P. Gans, A. Ienco, D. Peters, A. Sabatini and A. Vacca, Coordination Chemistry Reviews, 184 (1999) 311-318.

[18] P. May and K. Murray, http://jess.murdoch.edu.au/jess/jess_home.htm 
[19] F. Jones, A. Oliveira, G. M. Parkinson, A. L. Rohl, A. Stanley, T. Upson, J. Crystal Growth, 262 (2004) 572-580.

[20]a) R. J. Davey, S. N. Black, L. A. Bromley, D. Cottier, B. Dobbs and J. E. Rout, Nature, 353 (1991) 549-50. b) S. N. Black, L. A. Bromley, D. Cottler, R. J. Davey, B. Dobbs and J. E. Rout, J. Chem. Soc. Faraday Trans., 87(20) (1991) 3409-3414.

[21] J. R. Bargar, P. Persson and G. E. Brown Jnr., Geochim. et Cosmochim. Acta, 63(19/20) (1999) 2957-2969.

[22] E. Faulques, D. L. Perry, S. Lott, J. D. Zubkowski and E. J. Valente, Spectrochimica Acta A, 54 (1998) 869-878.

[23] K. Sawada, T. Miyagawa, T. Sakaguchi and K. Doi, J. Chem. Soc., Dalton Trans. (1993) 3777-3784, and references therein.

[24] F. Jones, A. Oliveira, G. M. Parkinson, A. L. Rohl, A. Stanley, T. Upson, J. Crystal Growth, 270 (2004) 593-603.

[25] E. Barouda, K. D. Demadis, S. R. Freeman, F. Jones, M. I. Ogden, Cryst. Growth \& Design, 7(2) (2007) 321-327.

[26] N. L. Allan, A. L. Rohl, D. H. Gay, C. R. A. Catlow, R. J. Davey, and W. C. Mackrodt, J. Chem. Soc., Faraday Discuss., 95 (1993) 273-280.

[27] "The Cambridge Structural Database: a quarter of a million crystal structures and rising” Allen, F. H., Acta Crystallogr. B58 (2002) 380-388.

[28] Jones, F., Oliveira, A., Rohl, A. L., Ogden, M. I., Parkinson, G. M. CrystEngComm 8(12) (2006) 869-876. 


\section{Tables}

Table 1. The measured de-supersaturation rate as EDTA concentration varies

\begin{tabular}{|lll|}
\hline EDTA $(\mathrm{mM})$ & Rate $\left(-1 \times 10^{-8} \mathrm{Scm}^{-1} \mathrm{~s}^{-1}\right)$ & $\%$ inhibited* \\
0 & 3.34 & 0 \\
0.016 & 2.79 & 16.5 \\
0.033 & 2.62 & 21.6 \\
0.049 & 2.43 & 27.2 \\
\hline
\end{tabular}

*calculated as (1 - measured rate/control rate)x100 


\section{Figure captions}

Figure 1. Schematic showing the EDTA molecule

Figure 2. Speciation graph of EDTA A) without barium ions present and B) with barium ions present

Figure 3. Barium sulfate precipitation as followed by A) conductivity and B) turbidity $(1 \mathrm{ppm}=$ $0.003 \mathrm{mM}, 5 \mathrm{ppm}=0.016 \mathrm{mM}, 15 \mathrm{ppm}=0.049 \mathrm{mM}$ and $50 \mathrm{ppm}=0.160 \mathrm{mM}$ )

Figure 4. Barium sulfate particles formed in the presence of A) $0 \mathrm{mM}$ EDTA (control) B) with $0.049 \mathrm{mM}$ EDTA and C) with $0.160 \mathrm{mM}$ EDTA

Figure 5. $\quad$ A) Barium sulfate particles formed in the presence of $0.160 \mathrm{mM}$ EDTA as viewed by TEM and B) the SAED pattern for the particle

Figure 6. Barium sulfate particles formed at $80{ }^{\circ} \mathrm{C}$. A) control particles, B) formed in the presence of $0.007 \mathrm{mM}$ EDTA (and allowed to age), C) formed in the presence of $0.049 \mathrm{mM}$ EDTA and filtered directly and D) formed in the presence of $0.160 \mathrm{mM}$ EDTA and filtered directly

Figure 7. Solution HATR spectra of $16.3 \mathrm{mM}$ EDTA at different pHs. Spectra have been offset (in the y-direction) for clarity.

Figure 8. HATR subtraction spectra of adsorbed EDTA on barium sulfate at the pHs shown. Spectra have been offset (in the y-direction) for clarity.

Figure 9. $\quad$ EDTA speciation curves in solution with calcium ions present

Figure 10. $\quad$ A) SEM of barite particles formed in the presence of calcium ions $(1.25 \mathrm{mM})$ and EDTA at $0.049 \mathrm{mM}$ and B) SEM of barite particles formed in the presence of EDTA at $0.049 \mathrm{mM}$ and $\mathrm{NaCl}$ to the equivalent ionic strength as $\mathrm{A}$ )

Figure 11. The most energetically favourable adsorption configurations of each additive on the (011) and (100a) barium sulfate faces investigated 


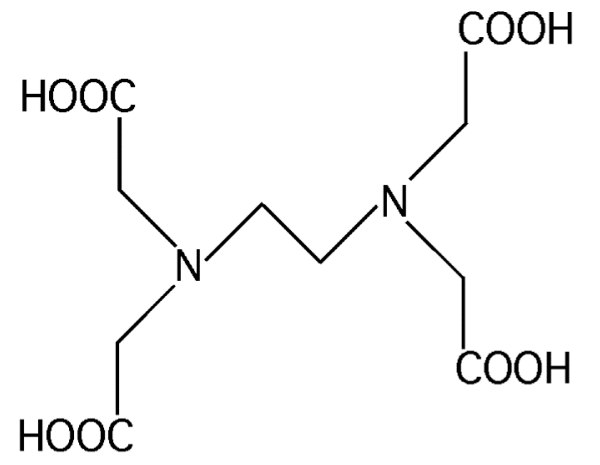

Figure 1. Schematic showing the EDTA molecule
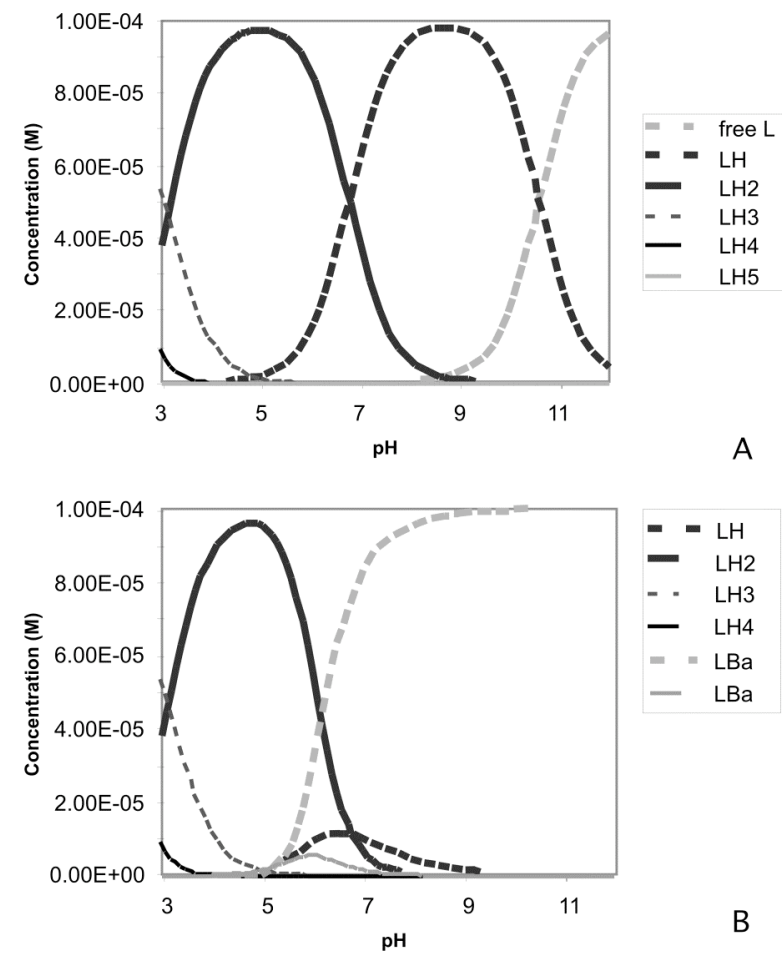

Figure 2. Speciation graph of EDTA A) without barium ions present and B) with barium ions present ( $\mathrm{L}$ refers to fully de-protonated ligand) 

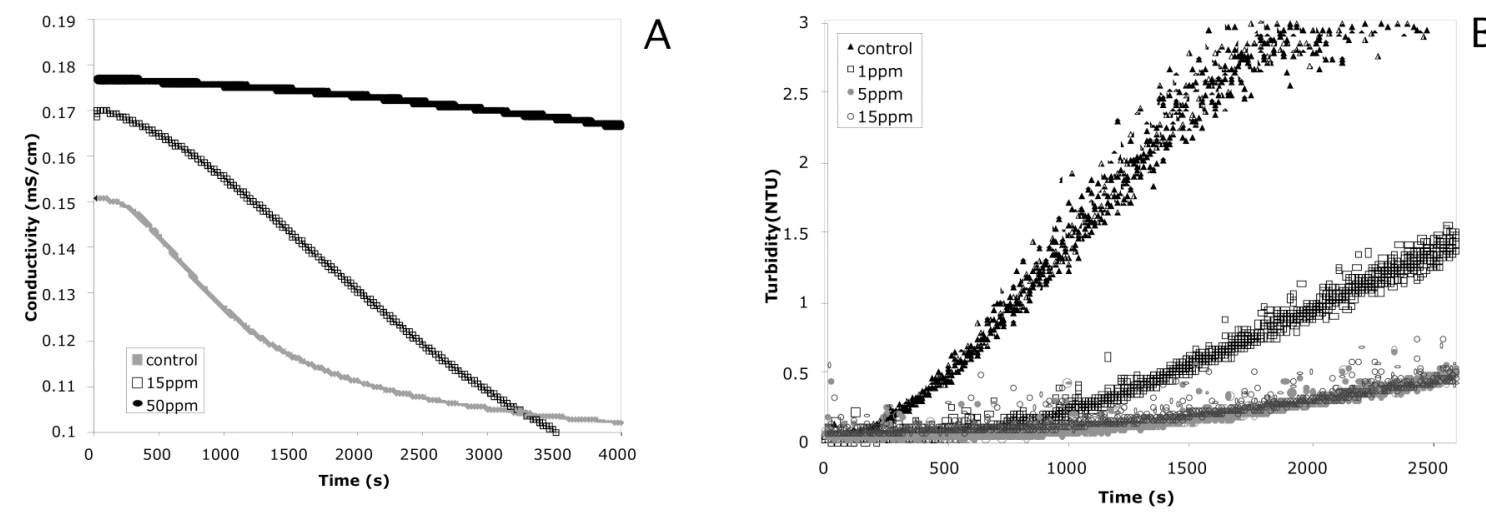

Figure 3. Barium sulfate precipitation as followed by A) conductivity and B) turbidity $(1 \mathrm{ppm}=$ $0.003 \mathrm{mM}, 5 \mathrm{ppm}=0.016 \mathrm{mM}, 15 \mathrm{ppm}=0.049 \mathrm{mM}$ and $50 \mathrm{ppm}=0.160 \mathrm{mM})$

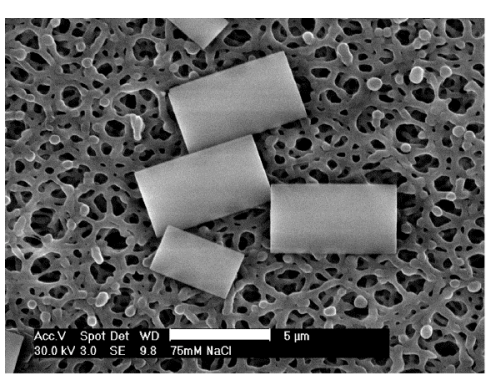

A

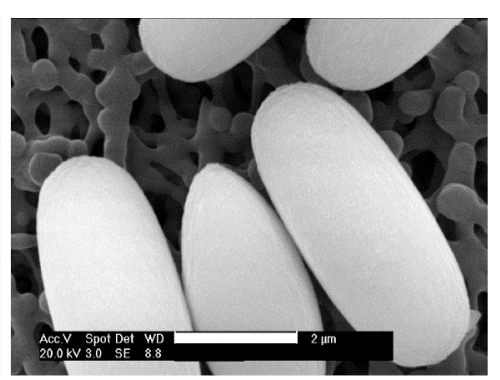

B

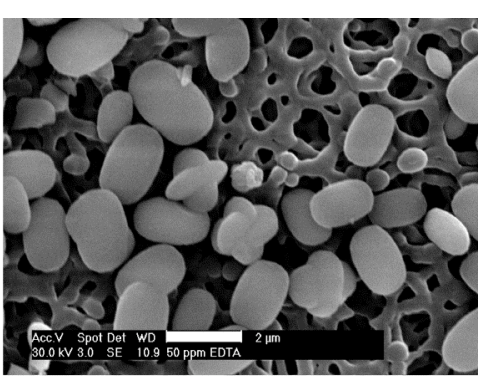

C

Figure 4. Barium sulfate particles formed in the presence of A) $0 \mathrm{mM}$ EDTA (control) B) with $0.049 \mathrm{mM}$ EDTA and C) with $0.160 \mathrm{mM}$ EDTA
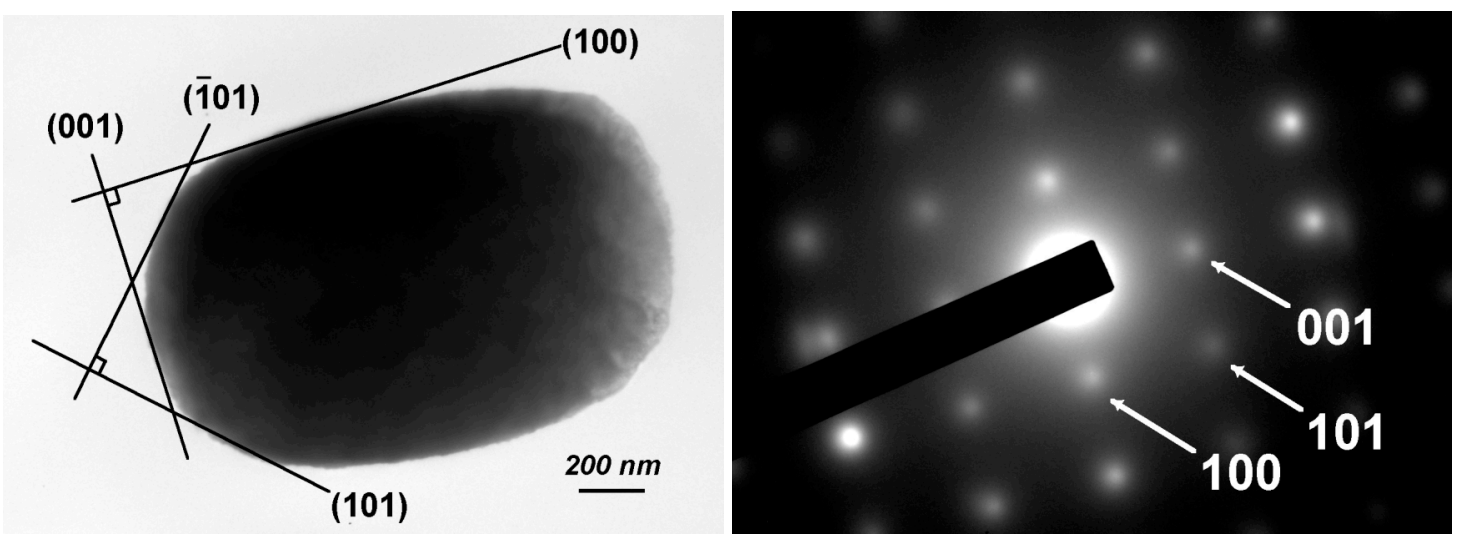

Figure 5. A) Barium sulfate particles formed in the presence of $0.160 \mathrm{mM}$ EDTA as viewed by TEM and showing the assignment of faces and B) the SAED pattern for the particle 


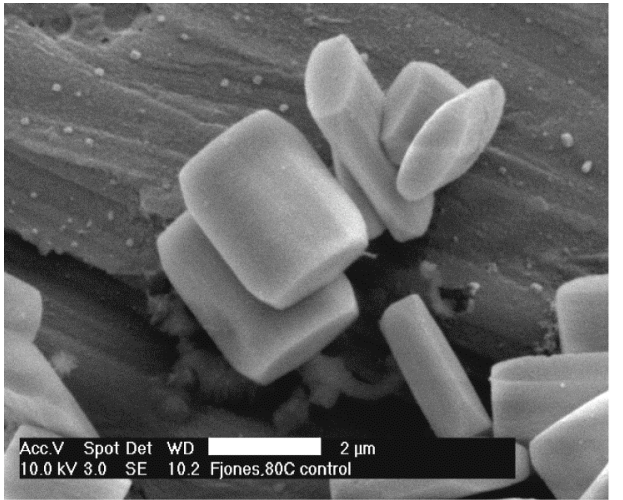

A

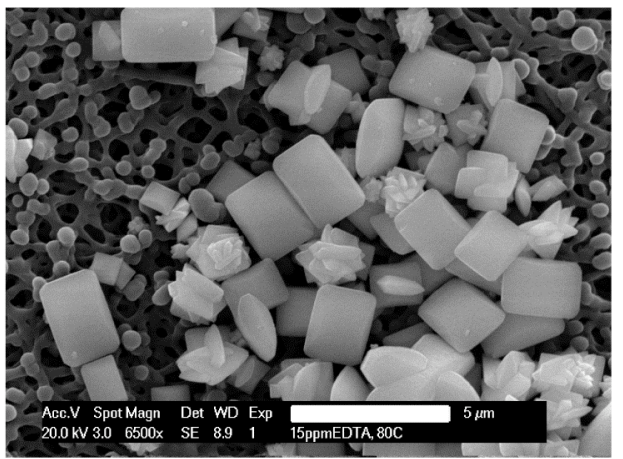

C

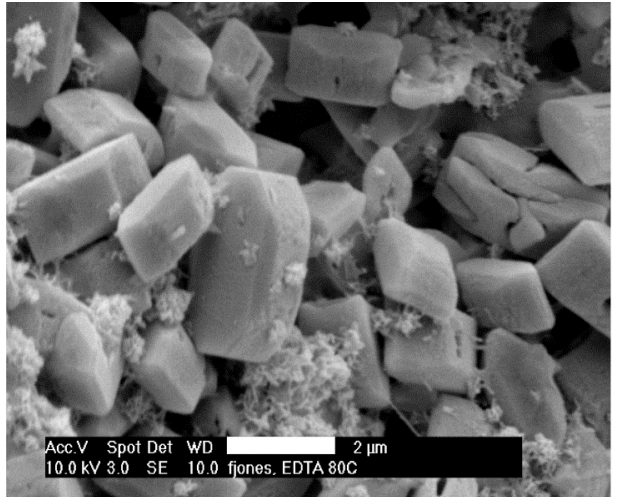

B

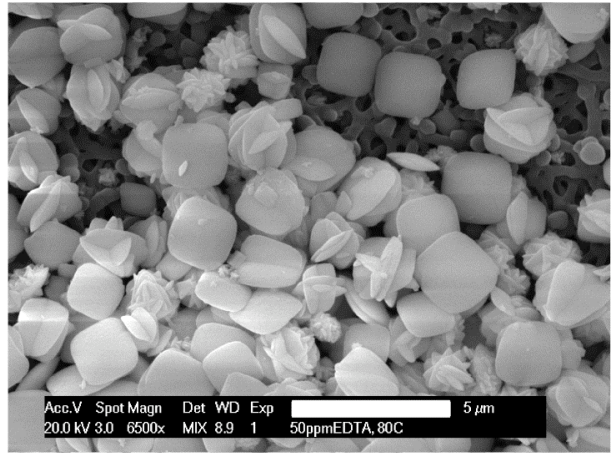

D

Figure 6. Barium sulfate particles formed at $80{ }^{\circ} \mathrm{C}$. A) control particles, B) formed in the presence of $0.007 \mathrm{mM}$ EDTA (and allowed to age), C) formed in the presence of $0.049 \mathrm{mM}$ EDTA and filtered directly and D) formed in the presence of $0.160 \mathrm{mM}$ EDTA and filtered directly

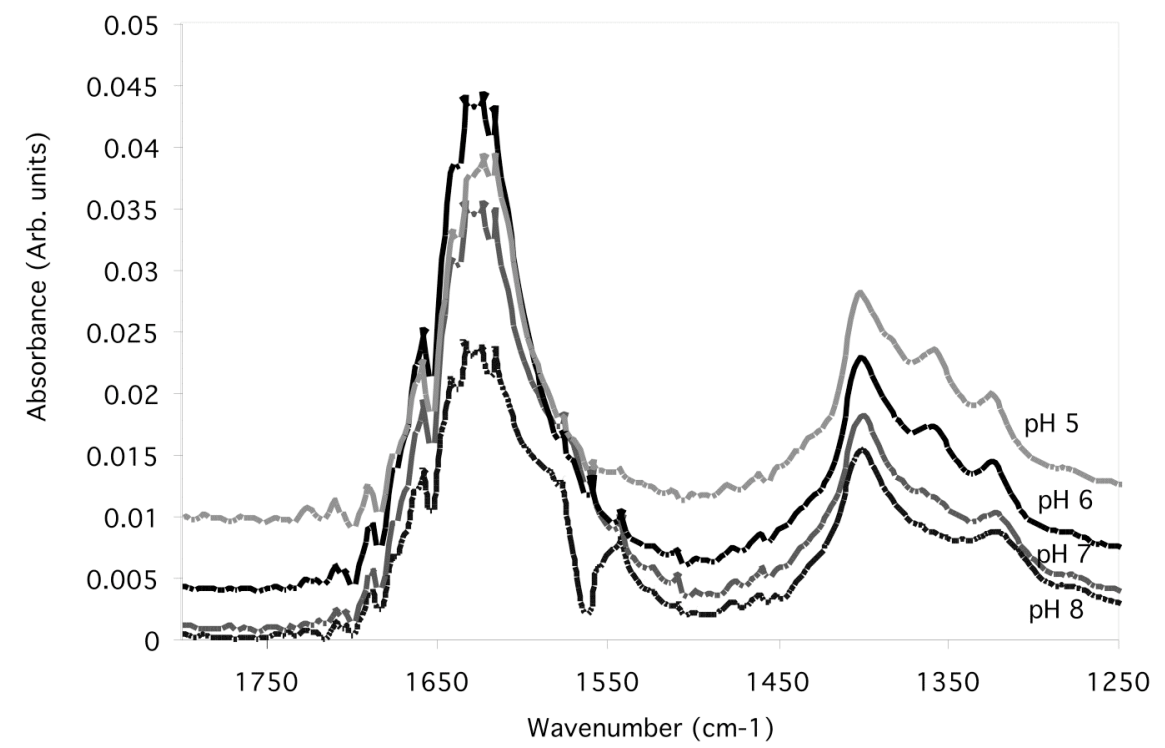

Figure 7. Solution HATR spectra of $16.3 \mathrm{mM}$ EDTA at different pHs. Spectra have been offset (in the y-direction) for clarity. 


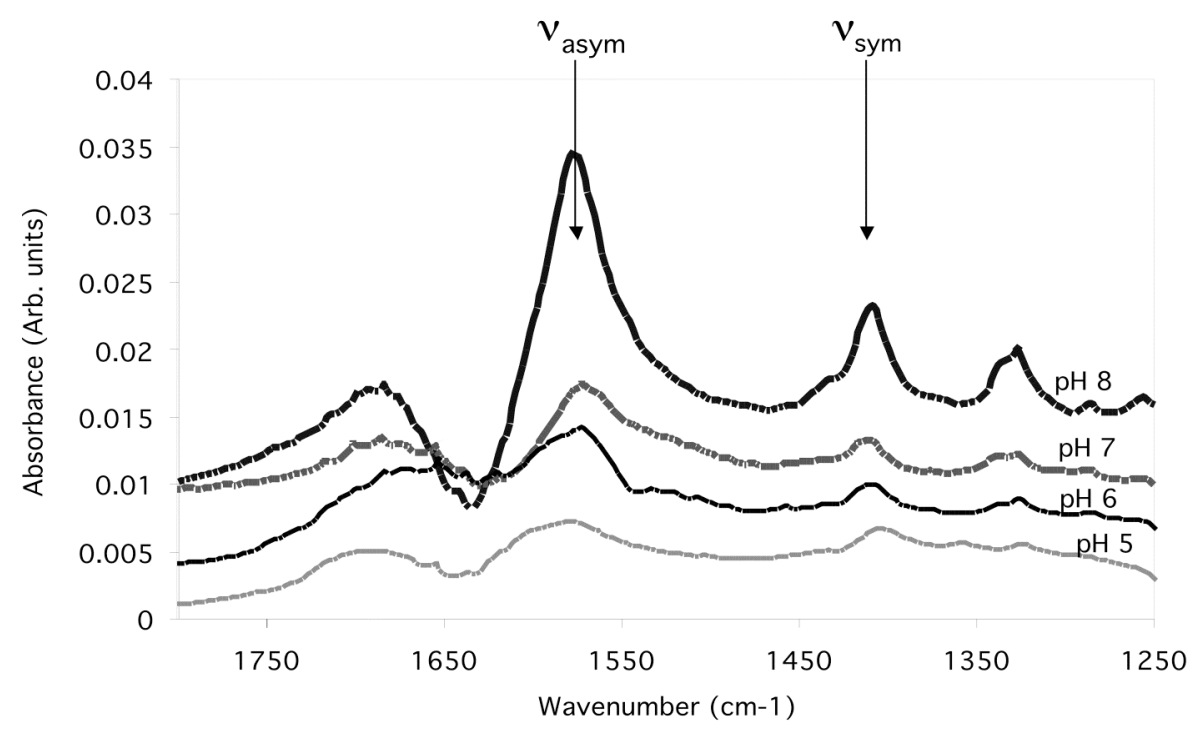

Figure 8. HATR subtraction spectra of adsorbed EDTA on barium sulfate at the pHs shown. Spectra have been offset (in the y-direction) for clarity.

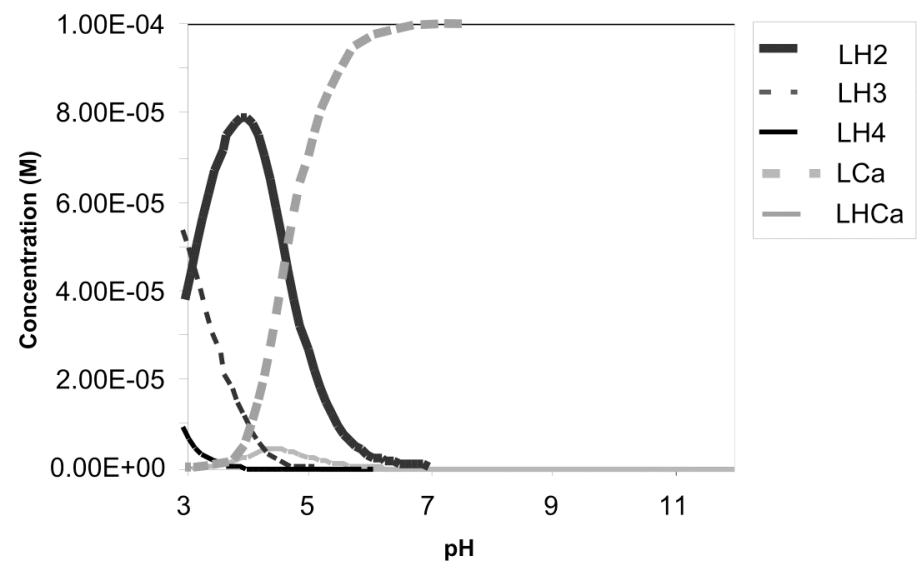

Figure 9. EDTA speciation curves in solution with calcium ions present (L refers to fully deprotonated ligand) 


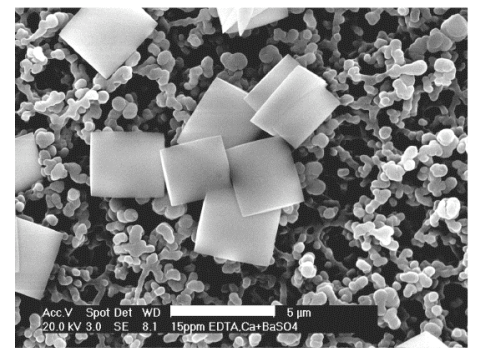

A

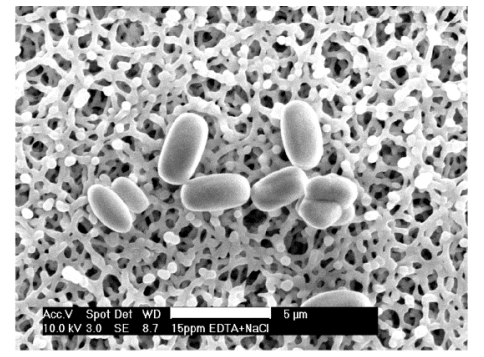

B

Figure 10. A) SEM of barite particles formed in the presence of calcium ions (1.25 $\mathrm{mM})$ and EDTA at $0.049 \mathrm{mM}$ and B) SEM of barite particles formed in the presence of EDTA at $0.049 \mathrm{mM}$ and $\mathrm{NaCl}$ to the equivalent ionic strength as $\mathrm{A}$ )
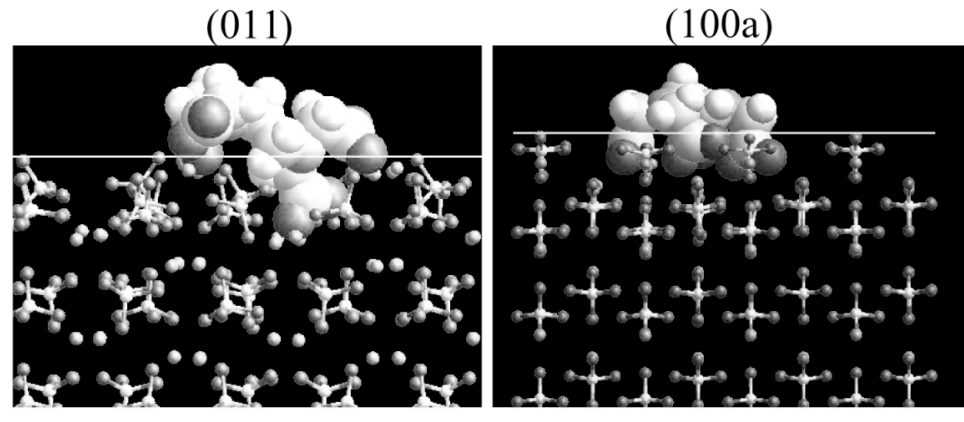

Figure 11. The most energetically favourable adsorption configurations of each additive on the (011) and (100a) barium sulfate faces investigated 